\title{
ENCAPSULATION OF PRECIPITATED CALCIUM CARBONATE FILLERS USING CARBOXYMETHYL CELLULOSE /POLYALUMINIUM CHLORIDE: PREPARATION AND ITS INFLUENCE ON MECHANICAL AND OPTICAL PROPERTIES OF PAPER
}

\author{
Hasan Mousavipazhouh ${ }^{1}$, Mohammad Azadfallah ${ }^{1,}$, Iman Rashidi Jouybari $^{1}$
}

\begin{abstract}
Inorganic fillers are usually used in papermaking industry to reduce production costs and enhance paper optical properties. As an attempt to improve fillers application in papermaking, carboxymethyl cellulose $(\mathrm{CMC})$ and poly aluminum chloride $(\mathrm{PAC})$ were used to encapsulate precipitated calcium carbonate (PCC) filler and modify its surfaces. In the first step, the optimum conditions for filler treatment (i.e. $\mathrm{pH}, \mathrm{CMC}$ and PAC contents) were obtained. Through the second step, different amounts of CMCencapsulated PCC were added to fiber suspension and some hand-sheets were made. Then, the effect of modified filler addition in different levels of 20,25, and 35\% on mechanical and optical properties of paper was investigated. The PAC dosage was found to be a critical factor for effective encapsulation of PCC fillers by carboxymethyl cellulose. When the dosages of CMC and PAC were $4 \%$ and $0.8 \%$ (based on the dry weight of PCC), respectively, filler modification caused to improve significantly the retention by more than twice. Strength properties of the hand-sheets fabricated with the $\mathrm{CMC} /$ PAC-modified PCC were also found to be significantly better than those obtained with the unmodified PCC at similar levels of filler content. In addition, the brightness and opacity of the filled papers at $30 \%$ addition of CMC-modified fillers were strikingly enhanced to 88,45 and $77 \%$, respectively. SEM observations of the filled papers also demonstrated that CMC-encapsulated filler particles were clustered and retained efficiently onto the fiber network. The present method for modification of PCC may provide an alternative approach to increase the filler amount in the paper structure by alleviating filler drawbacks.
\end{abstract}

Keywords: Brightness, filler modification, hand-sheets properties, Kraft pulp, opacity, paper strength.

\section{INTRODUCTION}

Paper is mainly composed of cellulosic fibers derived from renewable natural biomaterials including wood and non-wood lignocellulosic resources. Inorganic fillers are usually considered as the second most important component in producing the printing, writing and some other grades of papers (Zhao et al. 2008). Globally, the use of fillers in papermaking industries is now a very common procedure to meet the needs of papermakers. There are many advantages in filler addition, which mainly focuses on the cost reduction and energy savings (Dong et al. 2008, Shen et al. 2010), optical properties improvement (opacity and brightness), enhancing printability (ink holdout, greater levels of gloss, and better image quality), improving sheet uniformity, surface smoothness, and dimensional stability. Because of persistent economic pressure on cost reduction, inorganic fillers such as precipitated calcium carbonate (PCC) have become economically attractive in the papermaking process (Gaudreault et al. 2009). However, the use of fillers, especially at high loading levels, causes certain disadvantages or

${ }^{1}$ Department of Wood and Paper Science and Technology, Faculty of Natural Resources, University of Tehran, Karaj, Iran.

•Corresponding Author: adfallah@ut.ac.ir

Received: 14.02.2017 Accepted: 15.07.2018 
difficulties including deteriorated mechanical strength due to interference with inter-fiber bonding, decreased sizing efficiency, poor filler retention followed by increasing retention aid demand, twosidedness, abrasion (on wires, blade, etc.), and dusting tendency during printing (Gaudreault et al. 2009).

Many efforts have been reported to alleviate or overcome the drawbacks related to filler addition, including fillers incorporating into the lumens and/or cell walls of pulp fibers (Klungness et al. 2000), in situ precipitation of filler particles on fines/fibrils (Subramanian et al. 2007, Subramanian et al. 2008), using novel fillers such as starch-based biodegradable organic fillers, and fibrous/high-aspectratio inorganic fillers (Hu and Deng 2004, Mathur 2004, Mollaahmad 2008, Shen et al. 2010), use of functional strengthening agents (Chen et al. 2005, Fahmy and Mobarak 2009), fiber modification (Bratskaya et al. 2006, Kang 2007), and filler modification (Gill 1992, Laleg et al. 2008, Ibrahim et al. 2009, Shen et al. 2010, Marzbani et al. 2016). In recent years, filler modification methods have been specially focusing on biodegradable and renewable carbohydrate polymers (such as starch, cellulose, and chitosan) as a promising procedure in papermaking (Yoon and Deng 2007, Zhao et al. 2008, Deng et al. 2008, Nelson and Deng 2008, Shen et al. 2009, Song et al. 2009a, Song et al. 2009b). Pulp fibers, as the main component of paper is closely compatible with carbohydrate polymers and certain carbohydrate polymers are widely considered to be appropriate for usage in papermaking in order to enhance the paper properties (Fahmy 2007, Fahmy and Mobarak 2009, Fatehi et al. 2010).

Fillers, as the commonly used inorganic component in papermaking, are not generally capable of forming bonds with fibers and fines. Consequently, filler modification with carbohydrate polymers can improve the compatibility between fillers and fibers, and therefore can confer certain beneficial attributes of carbohydrate polymers to fillers. In a research conducted by Shen et al. (2010), PCC particles were modified by CMC/alum. The filler retention was improved by $71,5 \%$ in optimal conditions and the brightness and opacity of the filled paper were significantly enhanced. Yang et al. (2013) investigated the effect of filler modification by cationic starch and carboxymethyl cellulose. They reported that combination of cationic starch with CMC caused to improve attachment of the starch to filler surfaces. Furthermore, this enhanced mechanical and optical properties of paper. They asserted that modified filler provides an alternative approach to improve the use of mineral fillers in pulp and paper industries.

According to the recent studies, the benefits associated with the application of carbohydrate polymers in filler modification can include low cost, availability, environmental friendliness of the modifiers, enhanced paper strength, improved filler retention and in turn increased filler loading levels. Consequently, development of successful procedures can provide fruitful benefits to the papermaking industry.

Current study has focused on improving fiber-filler bonding through surface modification of very common used filler in papermaking i.e. PCC. The modification was carried out by encapsulation of PCC particles using carboxymethyl cellulose with natural compatibility and affinity with cellulosic pulp fibers through polymer precipitation with the aid of polyaluminum chloride (PAC). The study was carried out in 2 steps: First, the optimum conditions for filler modification were determined and at the second step, the effect of CMC/PAC-modified filler addition on mechanical and optical properties of hand-sheets was investigated.

\section{MATERIALS AND METHODS}

\section{Materials}

Bleached softwood Kraft pulp was purchased from U-ilimsk, Russia. It was refined by a PFI mill to $300 \mathrm{~mL}$ CSF prior to any treatment and making hand-sheets. The pulp fiber characteristics were measured using a Kajaani FS300 Fiber Analyzer (Metso Automation Inc., Finland), and the results are presented in Table 1. Carboxymethyl cellulose with degree of substitution approximately $0,65-0,90$ was purchased from Merk, Germany. Papermaking grade PCC filler known as Aragonite with density of $2,82 \mathrm{~g} / \mathrm{cm}^{3}$, ISO brightness of $92,4 \%$ and mean diameter of 5-6,5 $\mu \mathrm{m}$ was supplied from Neka 
Sang, Iran. Poly aluminum chloride with 28-31\% $\mathrm{AL}_{2} \mathrm{O}_{3}$ obtained from Falizan Tasfyeh Co. Ltd., Iran. Cationic poly Acrylamide denoted as CPAM was purchased from Yixing Cleanwater Chemicals Co., Ltd., Yixing, China. NaOH pellets with purity of $98 \%$ were purchased from Merck, Germany.

Table 1. Characteristics of pulp after refining.

\begin{tabular}{|c|c|c|}
\hline Fiber length $(\mathbf{m m})$ & Fiber width $(\boldsymbol{\mu m})$ & CSF $(\mathbf{m L} \mathbf{L}$ \\
\hline 1,93 & 30,4 & 300 \\
\hline
\end{tabular}

\section{Methods}

\section{Filler modification}

About $5 \mathrm{~g}$ PCC and $40 \mathrm{~mL}$ distilled water were added into a $300 \mathrm{~mL}$ round-bottom flask and the filler slurry stirred for 15 minutes to ensure sufficient mixing. Na-CMC powder was added slowly to deionized water at $60^{\circ} \mathrm{C}$ to obtain a uniform solution and then added to the filler slurry and stirred for $30 \mathrm{~min}$ in order to ensure uniform mixture. The freshly prepared $10 \%$ PAC solution was then instantly poured into the mixture, and the resulting mixture was further stirred at $700 \mathrm{rpm}$ for $40 \mathrm{~min}$. Finally the solid was separated by filtration and dried in a vacuum oven for 4 days.

The optimal conditions for preparation of the CMC-encapsulated PCC were selected after performing different pre-treatment trials as follows: $0,0,2 ; 0,4 ; 0,6 ; 0,8 ; 1$ and $2 \%$ PAC content (based on filler oven dried weight), 2, 4 and $6 \% \mathrm{CMC}$ (based on filler oven dried weight) and two slurry $\mathrm{pH}$ of 7,5 and 9,5. Furthermore, PCC was treated at the same conditions with $0,05 \%$ CPAM as a control in order to compare the effect of retention aid addition on paper properties.

\section{Hand-sheets}

The hand-sheets were prepared according to TAPPI T 205 sp-95 using Frank standard sheet mold. The target basis weight of hand-sheets was $60 \mathrm{~g} / \mathrm{m}^{2}$. For every experiment, 10 hand-sheets were made. Prior to mechanical and optical testing, they were conditioned for 24 hours at a temperature of $23^{\circ} \mathrm{C}$ and a relative humidity of $60 \%$.

\section{Characterization Methods}

\section{Measurement of mechanical properties}

In order to investigate the effect of CMC-modified PCC addition on mechanical properties of handsheets, tensile, burst, and tear strengths were measured according to ISO-1924-2, TAPPI T 403 om-97, and TAPPI T 414 om- 04, respectively. At least 3 replicate measurements were carried out to acquire each data.

\section{Opacity and brightness measurements}

To assess the effect of CMC-modified PCC addition on optical properties of paper, opacity and brightness measurements were carried out according to TAPPI T425 om-96 and ISO 2470-1, respectively.

\section{Scanning electron microscopy}

Scanning electron microscopy (SEM) images give a more direct view of the morphology of the PCC precipitates. All samples were examined using a MIRALL TESCAN at $7.0 \mathrm{kV}$. Prior to scanning, samples were coated with gold. 


\section{RESULTS AND DISCUSSION}

As mentioned before to find the better experimental conditions, in the first step, the effect of modifying PCC by $\mathrm{CMC}$ and PAC on hand-sheet properties was determined and corresponding optimum conditions were obtained. In the second step, the effect of filler application modified at optimal conditions on mechanical and optical properties of hand-sheets was investigated in different amounts of 20,25 , and $35 \%$.

\section{Optimizing the PAC content}

The PCC was treated with $4 \% \mathrm{CMC}$ in $\mathrm{pH}=7,5$ at different dosages of PAC. To determine the optimum range of PAC, about $20 \%$ (based on oven dried fiber weight) CMC-encapsulated PCC was added to pulp suspension. Furthermore, PCC with 0,05\% CPAM was used as a control to compare the effect of conventional retention aid addition on paper properties. Table 2 presents the effect of PAC dosages during encapsulation process on hand-sheet properties.

Table 2. Influence of PCC encapsulation with CMC using different Levels of PAC on retention, optical and mechanical properties of hand-sheets.

\begin{tabular}{|c|c|c|c|c|c|c|c|}
\hline Trials & $\begin{array}{c}\text { PAC } \\
(\%, \text { based on } \\
\text { PCC })\end{array}$ & $\begin{array}{l}\text { Tensile index } \\
(\mathrm{Nm} / \mathrm{g})\end{array}$ & $\begin{array}{c}\text { Burst index } \\
\left(\mathrm{kpa}^{2} / \mathrm{g}\right)\end{array}$ & $\begin{array}{c}\text { Tear } \\
\text { index } \\
\left(\mathrm{mNm}^{2} / \mathrm{g}\right)\end{array}$ & $\begin{array}{c}\text { Filler } \\
\text { retention } \\
(\%)\end{array}$ & $\begin{array}{c}\text { ISO } \\
\text { brightness } \\
(\%)\end{array}$ & $\begin{array}{c}\text { Opacity } \\
(\%)\end{array}$ \\
\hline \multirow{7}{*}{$\mathrm{PCC} / \mathrm{CMC}$} & 0 & 61,28 & 3,8 & 14 & 39,4 & 81,24 & 67,98 \\
\hline & 0,2 & 51,05 & 3,6 & 13,47 & 48,52 & 82,13 & 68,55 \\
\hline & 0,4 & 56,36 & 3,9 & 15,63 & 53,67 & 81,91 & 69,28 \\
\hline & 0,6 & 62,1 & 4,3 & 16,57 & 59,21 & 81,84 & 69,74 \\
\hline & 0,8 & 66,27 & 4,4 & 17,33 & 64,45 & 81,18 & 71,85 \\
\hline & 1 & 63,56 & 4,2 & 17,82 & 62,5 & 79,62 & 71,13 \\
\hline & 2 & 58,07 & 3,7 & 16,77 & 56 & 74,22 & 68,42 \\
\hline $\mathrm{PCC}+\mathrm{CPAM}$ & - & 59,41 & 3,6 & 13,35 & 48,23 & 80,87 & 69,34 \\
\hline $\begin{array}{c}\text { Without PCC } \\
\text { addition }\end{array}$ & - & 75,42 & 5,2 & 19,81 & 0,01 & 78,55 & 67,72 \\
\hline
\end{tabular}

\section{Paper strength}

According to the results, addition of CMC-modified fillers caused to maintain the overall strength properties of paper compared to control. As it was expected, the addition of modified and unmodified fillers gave rise to loss of strength. Maximum tensile and burst strength were obtained as $66,27 \mathrm{Nm} / \mathrm{g}$ and 4,4 Kpa. $\mathrm{m}^{2} / \mathrm{g}$ respectively, when PCC encapsulation was conducted with $0,8 \% \mathrm{PAC}$. Although, addition of PAC up to $0,8 \%$ improved the strength properties, but further increase in PAC dosage caused to impair the properties. Application of PAC up to $1 \%$ and resulted encapsulation also caused to enhance the tear strength, while at higher dosage of PAC i.e. $2 \%$ it was dropped slightly.

\section{Filler retention}

Based on the data, despite the application of PAC up to $0,8 \%$ has improved the retention by $64,45 \%$ further increase in PAC dosage decreased the retention value (Table 2).

\section{Optical Properties}

As can be seen from Table 2, no significant brightness changes were observed between $0,0,4 ; 0,6$ and $0,8 \%$ PAC dosages during PCC encapsulation process with CMC, however further increase caused to reduce the brightness of filled papers. The brightness loss may be attributed partly to the yellow nature of PAC and negative impact on scattering coefficient. On the contrary, the addition of PAC up to $0,8 \%$ led to enhance the opacity by $71,85 \%$ while further addition caused to decrease the opacity of papers. Consequently, in terms of contribution on optical properties, dosage of $0,8 \%$ PAC for PCC 
modification with $\mathrm{CMC}$ can be considered as an optimal value.

\section{Optimizing the CMC content}

After optimizing the PAC content $(0,8 \%), \mathrm{CMC}$ at 2,4 and $6 \%$ was targeted to determine the optimum value. The results are shown in Table 3.

Table 3. Influence of PCC Modification with Different Levels of CMC and 0,8\% PAC on Retention, Optical and Mechanical Properties of Hand-sheets.

\begin{tabular}{|c|c|c|c|c|c|c|}
\hline $\begin{array}{c}\text { CMC (\%, } \\
\text { based on } \\
\text { PCC) }\end{array}$ & $\begin{array}{c}\text { Tensile } \\
\text { index } \\
\mathbf{( N m / g )}\end{array}$ & $\begin{array}{c}\text { Burst index } \\
\left.\mathbf{( k p a . m}^{2} / \mathbf{g}\right)\end{array}$ & $\begin{array}{c}\text { Tear index } \\
\left.\mathbf{( m N m}^{2} \mathbf{g}\right)\end{array}$ & $\begin{array}{c}\text { Filler } \\
\text { retention } \\
\mathbf{( \% )}\end{array}$ & $\begin{array}{c}\text { ISO } \\
\text { brightness } \\
\mathbf{( \% )}\end{array}$ & $\begin{array}{c}\text { Opacity } \\
\mathbf{( \% )}\end{array}$ \\
\hline 2 & 59,18 & 4,1 & 15,23 & 41,41 & 78,59 & 68 \\
\hline 4 & 66,27 & 4,4 & 17,33 & 64,45 & 81,18 & 71,85 \\
\hline 6 & 67,49 & 4,5 & 18 & 56,42 & 82,33 & 69,43 \\
\hline
\end{tabular}

As it can be found from Table 3, addition of CMC up to $6 \%$ improved the strength properties of paper to the highest value. It is mainly because of improving the bonds between fibers and CMC coating on the surfaces of the modified fillers. For filler retention, application of $4 \% \mathrm{CMC}$ improved the retention value to $64,45 \%$ however, further addition of CMC decreased the retention. Likewise, the opacity of paper improved to $71,85 \%$ with a CMC content up to $4 \%$ while further addition decreased the value. Brightness, however, increased up to $82,33 \%$ by addition of $\mathrm{CMC}$ and $\mathrm{CMC}$ content of $6 \%$ improved brightness to the maximum value. It can be mainly attributed to the contribution of high brightness of used CMC, about $92 \%$. As a result, the optimum content of CMC was determined to be $4 \%$.

\section{Optimizing the pH}

In order to determine the optimum range of $\mathrm{pH}$ in filler modification, $\mathrm{PCC}$ was modified with $0,8 \%$ PAC and 4\% CMC under 2 different ranges of $\mathrm{pH}$. The results are shown in Table 4.

Table 4. Influence of PCC modification with $4 \% \mathrm{CMC}$ and $0,8 \% \mathrm{PAC}$ under two different $\mathrm{pH}$ on retention, optical and mechanical properties of hand-sheets.

\begin{tabular}{|c|c|c|c|c|c|c|}
\hline pH & $\begin{array}{c}\text { Tensile index } \\
\text { (Nm/g) }\end{array}$ & $\begin{array}{c}\text { Burst index } \\
\text { (kpa.m²/g) }\end{array}$ & $\begin{array}{l}\text { Tear index } \\
\left(\mathrm{mNm}^{2} / \mathrm{g}\right)\end{array}$ & $\begin{array}{c}\text { Filler } \\
\text { retention } \\
(\%)\end{array}$ & $\begin{array}{c}\text { ISO brightness } \\
(\%)\end{array}$ & $\begin{array}{c}\text { Opacity } \\
\text { (\%) }\end{array}$ \\
\hline 7,5 & 66,27 & 4,4 & 17,33 & 64,45 & 81,18 & 71,85 \\
\hline 9,5 & 63,56 & 4,1 & 16,45 & 61 & 80,52 & 70,62 \\
\hline
\end{tabular}

According to the results, the filler treatment at $\mathrm{pH}=7,5$ improves the overall properties of paper. In other words, increasing the $\mathrm{pH}$ not only decreased the mechanical properties relevant to this research, but it also diminished the filler retention and physical properties of hand-sheets. PAC contains high charge polymeric aluminum species as well as monomers. The $\mathrm{pH}$ affects the surface charge of PAC. It works effectively over a broader $\mathrm{pH}$ range of 5,0 to 8,0 (Fosso-Kankeu et al. 2017). Therefore, the improvement of encapsulation at $\mathrm{pH}=7,5$ is attributed to the increasing positive charges which enhance its neutralization ability. On the other hand, a decrease in the performance of polyaluminium chloride occurs when the $\mathrm{pH}$ tends towards more acidic or basic values followed by reduction in PAC solubility (Nasir and Daud 2014).

\section{SEM}

SEM images of unmodified and modified PCC filler are shown in Figure 1. As it is expected, the surface morphology of modified PCC filler was different from that of unmodified precipitated calcium carbonate filler, confirming the role of filler modification in structure change. Apparently, filler particles deposited on the fiber surfaces and modified PCC filler particles were clustered and adhered to the fiber surfaces possibly partly proving its better retention performance, in comparison to unmodified PCC filler particles. Furthermore, as can be seen from Figure 1(b), the encapsulation as a result of filler 
modification was quite evident. This can be also explained with rounder shape of modified particles. As shown in Figure 1, increasing fillers clustering and its association on the fiber surface which is in consistent with retention data (see Table 2 and Table 3) can be attributed to increased fillers affinity to fiber surfaces due to thin CMC shell of capsule which is more compatible with cellulosic fiber. Therefore, it can be concluded that an improvement in interfacial adhesion occurred between modified PCC and fiber surfaces.
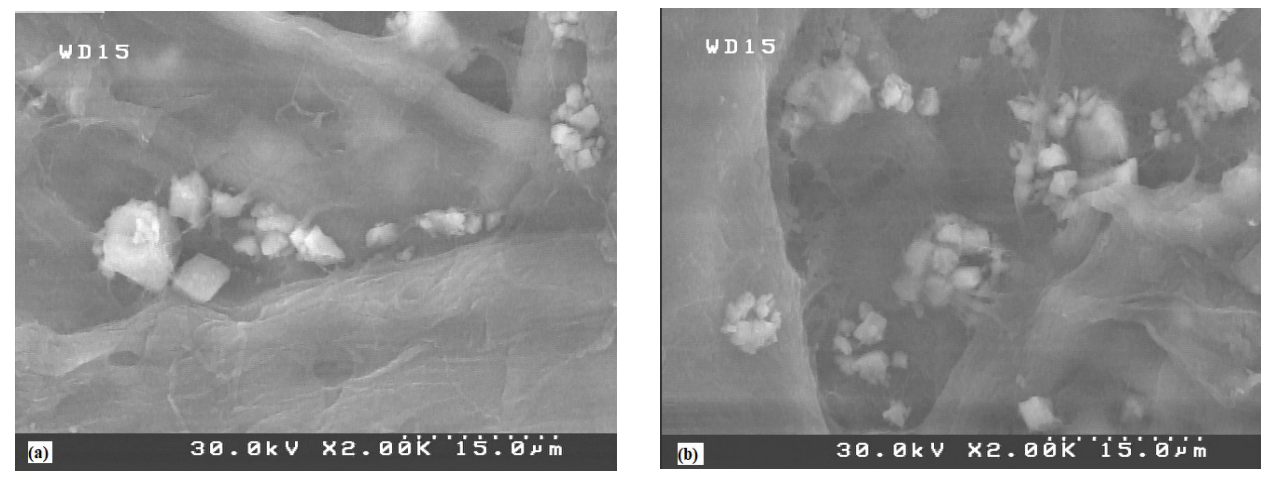

Figure 1. SEM images of paper-sheets filled with PCC: (a) unmodified precipitated calcium carbonate; (b) modified precipitated calcium carbonate under conditions of $4 \% \mathrm{CMC}, 0.8 \% \mathrm{PAC}$ and pH of 7,5 (magnification 2000x).

Based on the SEM observations, it is worth mentioning that, for PCC modification by CMC/PAC, the encapsulation of filler particles with precipitated CMC and the clustering of filler particles possibly decreased the opacity of the filler. However, strikingly increased filler retention as a result of filler modification contributed significantly to the improvement in optical properties especially opacity of the paper. Also, as the refractive index of $\mathrm{Al}(\mathrm{OH})_{3}$ precipitates is higher than that of cellulosic pulp fibers, its formation might possibly introduce certain contribution to optical improvement. As a result, it can be inferred that filler modification process was successful. When CMC and PAC were used as modifiers, not only the surface encapsulation of filler was feasible, but also beneficial.

\section{Determining the filler content modified in optimum conditions on hand-sheet properties}

In this step, the effect of modified PCC in optimum modification conditions $(4 \% \mathrm{CMC}$ and $0,8 \% \mathrm{PAC}$, and $\mathrm{pH}=7,5)$ on paper mechanical and physical properties in different filler content levels of 20,25 , and $35 \%$ was investigated.

\section{Tensile strength}

Many process parameters in papermaking affect the tensile strength (Okan et al. 2015). It is certainly the property that responds most to inter-fiber bonding. The effect of filler application in different levels on tensile strength of hand-sheets is shown in Figure 2.

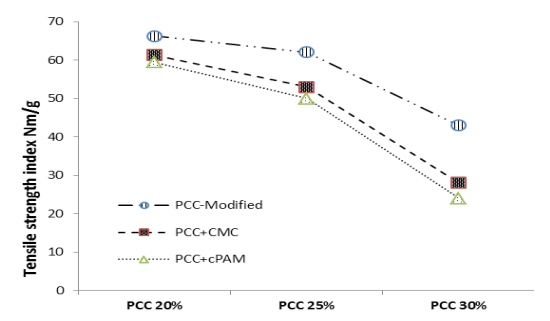

Figure 2. The effect of different addition levels of PCC modified with $4 \%$ CMC, $0,8 \%$ PAC in $\mathrm{pH}=7,5$ on tensile index. 
Hand-sheets filled with CMC/PAC-modified PCC exhibit an improvement in the tensile strength which is greater than the simple CMC-modified PCC or PCC/CPAM values for all addition levels. As shown in Figure 2, increasing in filler contents resulted in decreasing tensile strength in all samples. It may be attributed to the detrimental effects of fillers on formation of fiber-fiber bonds in paper network. However, because of improving compatibility of modified PCC with fibers followed by boosting fiberfiller-fiber bonds, further strength loss was hindered in spite of increasing filler loading into the sheets. Tensile strength mainly depends on bonding area, degree of bonding and bonding strength between fibers. In another research conducted by Yoon and Deng (2007), it was found that modified filler had less impact on tensile strength reduction in comparison to unmodified filler.

\section{Burst strength}

Burst index also responds to the inter-fiber bonding due to the multidimensional aspect of this method, but to a higher extent than the tensile strength. Therefore, it is much sensitive to evaluate debonding effects of fillers by measuring pressure needed to rupture the paper. The result achieved by burst strength test is illustrated in Figure 3.

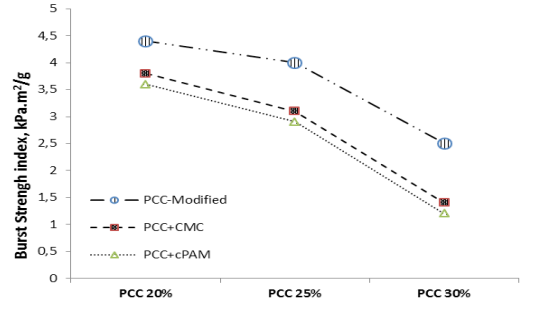

Figure 3. The effect of different addition levels of PCC modified with $4 \%$ CMC $0,8 \%$ PAC in $\mathrm{pH}=7,5$ on burst index.

When comparing the performance of fillers, for similar filler contents, it is possible to verify that, the hand-sheets burst strength decreases and follows the same trend as tensile strength (Figure 3). This is a consequence of the formation of a more open sheet structure with a smaller relative amount of fibers and also a smaller fiber-to-fiber bonding degree. It can also be found that papers filled with modified PCC in comparison with unmodified fillers exhibit higher burst strength in all levels of filler addition. As shown in Figure 3, papers containing PCC/CPAM showed the lowest values for burst strength, however, PCC/CMC treated hand-sheets showed better characteristic. It can be attributed to the intimate nature of $\mathrm{CMC}$ with cellulose fibers and its potential as a good strength agent due to formation of hydrogen bonds. The results obtained for burst strength correspond with those obtained by Yoon and Deng (2007), and Shen et al. (2010), asserting that application of modified filler induces less decrease in strength properties of paper in comparison with unmodified filler.

\section{Tear strength}

Tear strength of paper depends on the fiber strength, which is a property of instinct nature of fiber as well as fiber length and flexibility (Casey 1981, Marzbani et al. 2016, Akeem-Azeez et al. 2016). The effect of different addition levels of CMC/PAC modified PCC, unmodified PCC and PCC/CPAM on tear strength are shown in Figure 4.

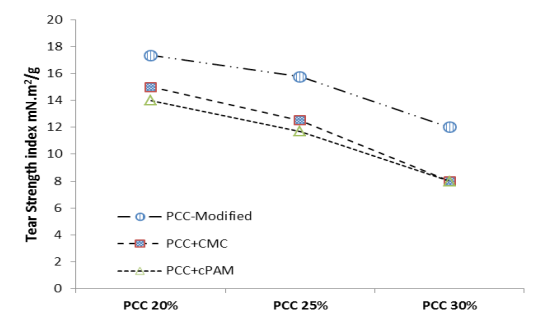

Figure 4. The effect of different addition levels of PCC modified with $4 \% \mathrm{CMC} 0,8 \%$ PAC in $\mathrm{pH}=7,5$ on tear index. 
As shown in Figure 4, by increasing the filler content in all trials, the tear strength decreased. However, for PCC modified with CMC/PAC, strength loss was moderate in comparison with other experiments. Notably, at filler content of $35 \%$, both unmodified PCC/CMC and PCC/CPAM filled paper reached to the same values. It seems that making the interface of cellulosic material and minerals much compatible through surface modification cause to alleviate the adverse effect of mineral fillers on paper strength. The maximum tear strength value $\left(17,33 \mathrm{mN} . \mathrm{m}^{2} / \mathrm{g}\right)$ was obtained at filler content of $20 \%$ for CMC/PAC modified-PCC, i.e. an improvement of $15,52 \%$ in comparison with unmodified PCC/CMC was achieved. In similar study, Zhao et al. (2005) found that tear strength was considerably deteriorated by increasing filler content, however, it was less obvious for modified filler. In other study by Shen et al. (2010), it was reported that at $20 \%$ of filler content, modified filler improved the tear strength from 24,43 to $37,26 \mathrm{mN} . \mathrm{m}^{2} / \mathrm{g}$, i.e. about $52,51 \%$ gain was achieved. It was concluded that filler modification resulted in developing the tear strength.

\section{Filler retention}

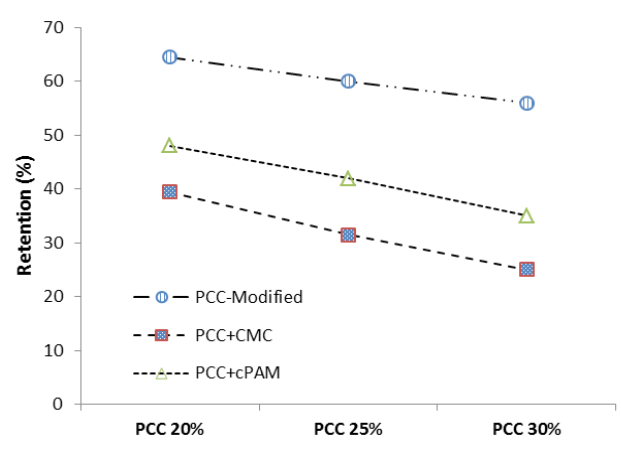

Figure 5. The effect of different addition levels of PCC modified with $4 \%$ CMC $0,8 \%$ PAC in $\mathrm{pH}=7,5$ on filler retention.

The retention of fillers has long been a hot topic in the research field of wet end chemistry. It is well known that the retention efficiency significantly influences the cost of the product, cleanliness of the papermaking system, and contaminant load of the system (Vengimalla et al. 1999). Therefore, it is quite necessary to investigate the retention performances of unmodified and modified precipitated calcium carbonate fillers. The effect of different filler content levels on retention is presented in Figure 5.

Compared to unmodified PCC/CMC, the retention of PCC/CMC/PAC- modified filler is much higher. Furthermore, $35 \%$ filler content further improved it by more than 2 -folds. It is worth mentioning that the filler retention efficiency of CPAM exceeded that of unmodified PCC/CMC. In various efforts to maintain the filler content in paper mills, it was found that the efficiency of retention aids highly depends on the type of retention aid, suspension dispersion, fiber-retention aid-filler bonding, in-situ paper web conforming, etc. Fillers put some restrictions on the absorption of retention aids and besides increasing process water loadings, excess consumption of the retention aids yield no corresponding improvement on the filler retention. Therefore, if fillers are coated or treated with some bonding materials, the surface absorption capability will increase and results in significant improvement of the filler retention (Yoon and Deng 2007). In a similar research carried out by Yang et al. (2013), it was revealed that application of CMC as modifier to PCC can only develop the retention up to $15 \%$, however, addition of cationic starch as retention aid significantly improve the properties.

\section{Brightness}

Application of filler not only decreases the manufacture costs, but also improves the paper optical properties. It has to be taken into account considering new achievements in technology that resulted in further usage of fillers. It is well known that $\mathrm{TiO}_{2}$ and $\mathrm{PCC}$ have the maximum brightness in comparison with others. The effect of different addition levels of fillers on brightness properties of hand-sheets are 
illustrated in Figure 6.

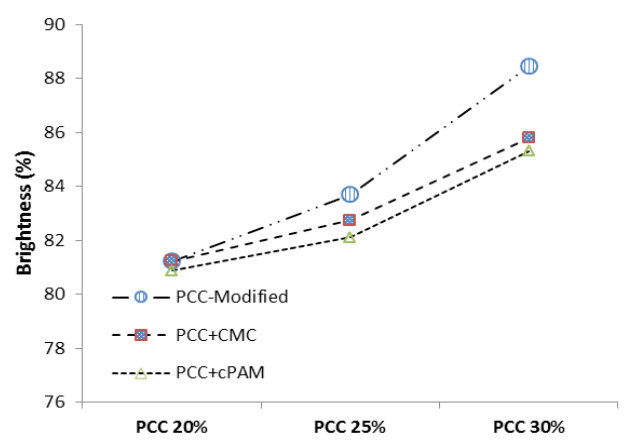

Figure 6. The effect of different addition levels of PCC modified with 4\% CMC 0,8\% PAC in $\mathrm{pH}=7,5$ on brightness.

According to Figure 6, it can be confirmed that fillers had positive effect on properties and further increase in filler content for all trials has considerably improved the brightness of paper. CMC/PACmodified PCC showed better performance in comparison with unmodified PCC/CMC. The lowest brightness value was obtained for PCC/CPAM filler. The best result was obtained with a filler content of $35 \%$ and CMC/ PAC-modified PCC $(88,45 \%)$. Notably, further addition of CMC/PAC-modified fillers improved the properties by $9,3 \%$. Similarly, Yan et al. (2005) reported that using starch and clay raises the brightness up to $76 \%$.

\section{Opacity}

Opacity is one of the most vital properties of printing and writing papers. The effect of filler modification on hand-sheet properties is presented in Figure 7.

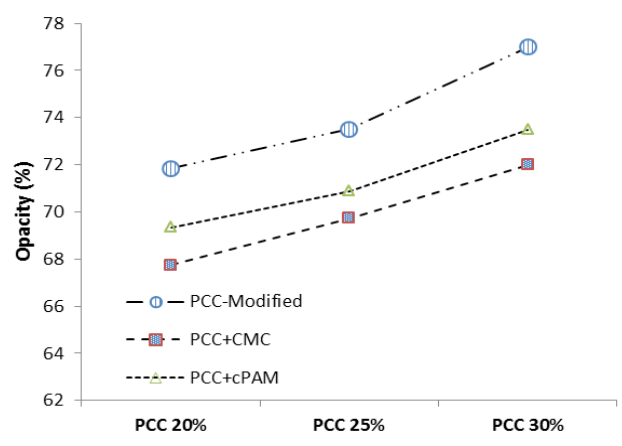

Figure 7. The effect of different addition levels of PCC modified with $4 \%$ CMC $0,8 \%$ PAC in $\mathrm{pH}=7,5$ on opacity.

Previous studies have shown that paper opacity improves by increasing the filler content (Song et al. 2009a, Song et al. 2009b, Lourenço et al. 2014). Although, application of filler results in decreasing the bond-ability between fibers but, it causes to create more optically active pores. Therefore, the greater number of optically active pores cause to the more light-scattering and the opacity. As shown in Figure 7, CMC/PAC-modified fillers exhibited better performance on opacity in all filler content in comparison with other trials. The maximum opacity value of $77 \%$ was achieved by CMC/PAC-modified filler at $30 \%$ content, an improvement of $7,16 \%$ compared with the filler content of $20 \%$. PCC/CMC showed low efficiency in comparison with PCC/CPAM to improve the paper opacity. The results are in consistent with those achieved by filler retention experiments. In other words, further retention of fillers develops opacity of paper directly. In this regard, Yang et al. (2013), reported that application of $20 \%$ modified PCC fillers using combination of cationic starch and carboxymethyl cellulose caused to 
improve the opacity from 78 to $85 \%$ due to filler retention enhancement.

\section{CONCLUSIONS}

In this research, following results were achieved:

1- The optimum conditions for PCC filler modifications by CMC, PAC and $\mathrm{pH}$ were determined as $4 ; 0,8 \%$ (based on filler oven dried weight) and 7,5 respectively.

2- In the presence of PAC, carboxymethyl cellulose was confirmed to be suitable for application in the encapsulation of papermaking grade precipitated calcium carbonate filler.

3- When the dosages of carboxymethyl cellulose and PAC were $4 \%$ and $0,8 \%$ (based on the dry weight of PCC) respectively, filler modification improved filler retention by as high as more than 2 times and the brightness and opacity (optical properties) of the filled paper was significantly enhanced, while the mechanical strength properties were negatively influenced.

4- Filler encapsulation by modifiers was confirmed through SEM observations. Compared with the unmodified filler particles, SEM images of the paper-sheets indicated that the modified precipitated calcium carbonate filler particles were clustered and bonded to the fiber surfaces.

\section{REFERENCES}

Akeem-Azeez, M.; Andrew, J.E.; Sithole, B.B. 2016. A preliminary investigation of nigerian Gmelina arborea and Bambusa vulgaris for pulp and paper production. Maderas-Cienc Tecnol 18(1):65-78.

Bratskaya, S.; Schwarz, S.; Petzold, G.; Liebert, T.; Heinze, T. 2006. Cationic starches of high degree of functionalization: 12. Modification of cellulose fibers toward high filler technology in papermaking. Industrial and Engineering Chemistry Research 45(22): 7374-7379.

Casey, J.P. 1981. Pulp and Paper Chemistry and Technology. ( $3^{\text {rd }}$ Ed., Vol. 3), John Wiley and Sons Inc., New York, USA.

Chen, X.N.; Huang, R.X.; Pelton, R. 2005. The reinforcement of calcium carbonate filed papers with phosphorous-containing polymers. Industrial and Engineering Chemistry Research 44(7): 20782085.

Deng, Y.L.; Ragauskas, A.J.; White, D.; Yoon, S. 2008. US Patent No. 20080087396. Washington, DC, USA: US Patent Office.

Dong, C.; Song, D.; Patterson, T. 2008. Energy saving in papermaking through filler addition. Industrial and Engineering Chemistry Research 47: 8430-8435.

Fahmy, T.Y.A. 2007. Introducing molasses as a new additive in papermaking. TAPPI Journal 6(8): 23-25.

Fahmy, T.Y.A.; Mobarak, F. 2009. Advanced nano-based manipulations of molasses in the cellulose and paper discipline: Introducing a master cheap environmentally safe retention aid and strength promoter in papermaking. Carbohydrate Polymers 77(2): 316-319.

Fosso-Kankeu, E.; Webster, A.; Ntwampe, I.O.; Waanders, F.B. 2017. Coagulation/flocculation potential of polyaluminium chloride and Bentonite clay tested in the removal of methyl red and crystal violet. Arabian Journal for Science and Engineering 42:1389-1397. 
Fatehi, P.; Kititerakun, R.; Ni, Y.; Xiao, H. 2010. Synergy of CMC and modified chitosan on strength properties of cellulosic fiber network. Carbohydrate Polymer 80(1): 208-214.

Gaudreault, R.; Di Cesare, N.; Weitz, D.; Van De Ven, T.G. 2009. Flocculation kinetics of precipitated calcium carbonate. Colloids and surfaces A: Physicochemical and Engineering Aspects 340: $56-65$.

Gill, R.A. 1992. Cationic polymer-modified filler material, process for its preparation and method of its use in papermaking. U. S. Patent No. US5147507 A.

Hu, Z.; Deng, Y. 2004. Synthesis of needle like aragonite from calcium chloride and sparingly soluble magnesium carbonate. Powder Technology 140:10-16.

Ibrahim, M.A.; Mobarak, F.; El-Din, E.I.S.; Ebaid, A.E.E.; Youssef, M. A. 2009. Modified Egyptian talc as international and surface treatments for papermaking. TAPPI Journal 8(4): 15-22.

Kang, T. 2007. Role of External Fibrillation in Pulp and Paper Properties, Ph.D. Dissertation, Helsinki University of Technology, Helsinki, Finland.

Klungness, J.H.; Ahmed, A.; Ross-Sutherland, N.; Abu Bakr, S. 2000. Lightweight, highopacity paper by fiber loading: Filler comparison. Nordic Pulp \& Paper Research Journal 15: 345-350.

Laleg, M.; Collins, R.; Gagne, D.; Middleton, S. 2008. Latex-treated filler slurries for use in papermaking. WIPO Patent Application WO/2008/148204, Dec. 11.

Lourenço, A.F.; Gamelas, J.A. F.; Ferreira, P.J. 2014. Increase of the filler content in papermaking by using a silica-coated PCC filler. Nordic Pulp \& Paper Research Journal 29 (2): 242-27.

Marzbani, P.; Resalati, H.; Ghasemian, A; Shakeri, A. 2016. Surface modification of talc particles with phthalimide: study of composite structure and consequences on physical, mechanical, and optical properties of deinked pulp. BioResources 11(4): 8720-8738.

Mathur, V.K. 2004. Multi-phase calcium silicate hydrates, methods for their reparation, and improved paper and pigment products produced therewith. U.S. Patent No. US6726807B1.

Mollaahmad, M.A. 2008. Sustainable fillers for paper. M. Sc. Thesis, Lulea University of Technology, Sweden.

Nasir, N.; Daud, Z. 2014. Performance of aluminum sulphate and polyaluminium chloride in biodiesel wastewater. Journal of Mechanical Engineering and Sciences (JMES) 7: 1189-1195.

Nelson, K.; Deng, Y. 2008. Enhanced bondability between inorganic particles and a polysaccharide substrate by encapsulation with regenarted cellulose. Journal of Applied Polymer Science 107:28302836.

Okan, O.T.; Deniz, I.; Tiryaki, S. 2015. Application of artificial neural networks for predicting tensile index and brightness in bleaching pulp. Maderas-Cienc Tecnol 17(3): 571 - 584 .

Shen, J.; Song, Z.; Qian, X.; Liu, W. 2009. Modification of papermaking grade fillers: A brief review. BioResources 4(3): 1190-1209.

Shen, J.; Song, Z.; Qian, X.; Liu, W.; Yang, F. 2010. Fillers and the carbon footprint of papermaking. BioResources 5 (4):2026-2028.

Song, D.; Dong, C.; Ragauskas, A.J.; Deng, Y. 2009a. Filler modification engineering for 
improved paper properties and papermaking process. In: TAPPI $2^{\text {nd }}$ Annual Paper Conference: Solutions for a Changing World, St. Louis, USA.

Song, D.; Dong, C.; Ragauskas, A.J.; Deng, Y. 2009b. Filler modification with polysaccharides or their derivatives for improved paper properties. Journal of Biobased Materials and Bioenergy 3(4): 321-334.

Subramanian, R.; Fordsmand, H.; Paulapuro, H. 2007. Precipitated calcium carbonate (PCC)cellulose composite fillers: Effect of pcc particle morphology on the production and properties of uncoated fine paper. BioResources 2: 91-105.

Subramanian, R.; Fordsmand, H.; Paltakari, J.; Paulapuro, H. 2008. A new composite fine paper with high filler loading and functional cellulosic microfines. Journal of Pulp and Paper Science 34: 146-152.

Vengimalla, R.; Chase, G.G.; Ramarao, B.V. 1999. Modeling of filler retention in compressible fibrous media. Separation and Purification Technology 15: 153-161.

Yan, Z.; Liu, Q.; Deng, Y. 2005. Improvement of paper strength with starch modified clay. Journal of Applied Polymer Sciences 97: 44-50.

Yang, H.; Qiu, L.; Qian, X.; Shen, J. 2013. Filler Modification for Papermaking with Cationic Starch and Carboxymethyl Cellulose: A Comparative Study. BioResources 8(4): 5449-5460.

Yoon, S.Y.; Deng, Y. 2007. Experimental and modeling study of the strength properties of claystarch composite filled papers. Industrial and Engineering Chemistry Research 46(14): 4883-4890.

Zhao, Y.; Hu, Z.; Ragauskas, A.J.; Deng, Y. 2005. Improvement of paper properties using starchmodified precipitated calcium carbonate filler. TAPPI Journal 4(2): 3-7.

Zhao, Y.; Kim, D.; White, D. 2008. Developing a new paradigm for linerboard fillers. TAPPI Journal 7: 3-7. 